\title{
A RADIOMAGNETOTELLURIC SURVEY AT THE IDAHO NATIONAL ENGINEERING LABORATORY COLD TEST PIT
}

\author{
Bülent Tezkan, Stephan Dautel
}

Institut für Geophysik und Meteorologie, Universität zu Köln, Germany Tel: (+49)-221-470 3386 Fax: (+49)-221-470 5198 e-mail: tezkan@geo.uni-koeln.de

\section{Louise Pellerin}

Lawrence Berkeley National Laboratory, Berkeley, CA 94720, USA

\section{Introduction}

Many gravel pits have been filled in the last 50 years with household refuse, building debris and industrial waste. They were filled up in an uncontrolled manner with poor or no documentation. Nowadays most of these waste sites are covered by thin gravel and soil layer and are recultivated. However, they bear a huge risk to the environment due to the possible pollution of the aquifers. Therefore the detection of the dimensions of a waste site and especially the determination of different regions inside a waste site are very important for environmental protection studies.

The Idaho National Laboratory Cold Test Pit has been constructed to simulate hazardous waste occurences (Pellerin et. al., 1997). The mix of cardboard and metal drum was used to simulate an old waste pit. Variable cap material is 1-2 meters thick. The bottom of the waste site is approximatelly $8 \mathrm{~m}$. Four profiles over the box and drum cells, called the primary lines were used. South of this area (Large Object Pit) different type of anomalies ( boxes, steel tank..) have been burried. A 2D grid over the Large Object Pit (LOP) were used (Fig.1). Line spacings was 5 feet and the distance between the stations was also 5 feet. The aim of the study is to examine the resolution of several electromagnetic techniques for the detection of lateral and vertical boundaries of the waste site and the resolution of different type of anomalies in the waste site under known conditions. 


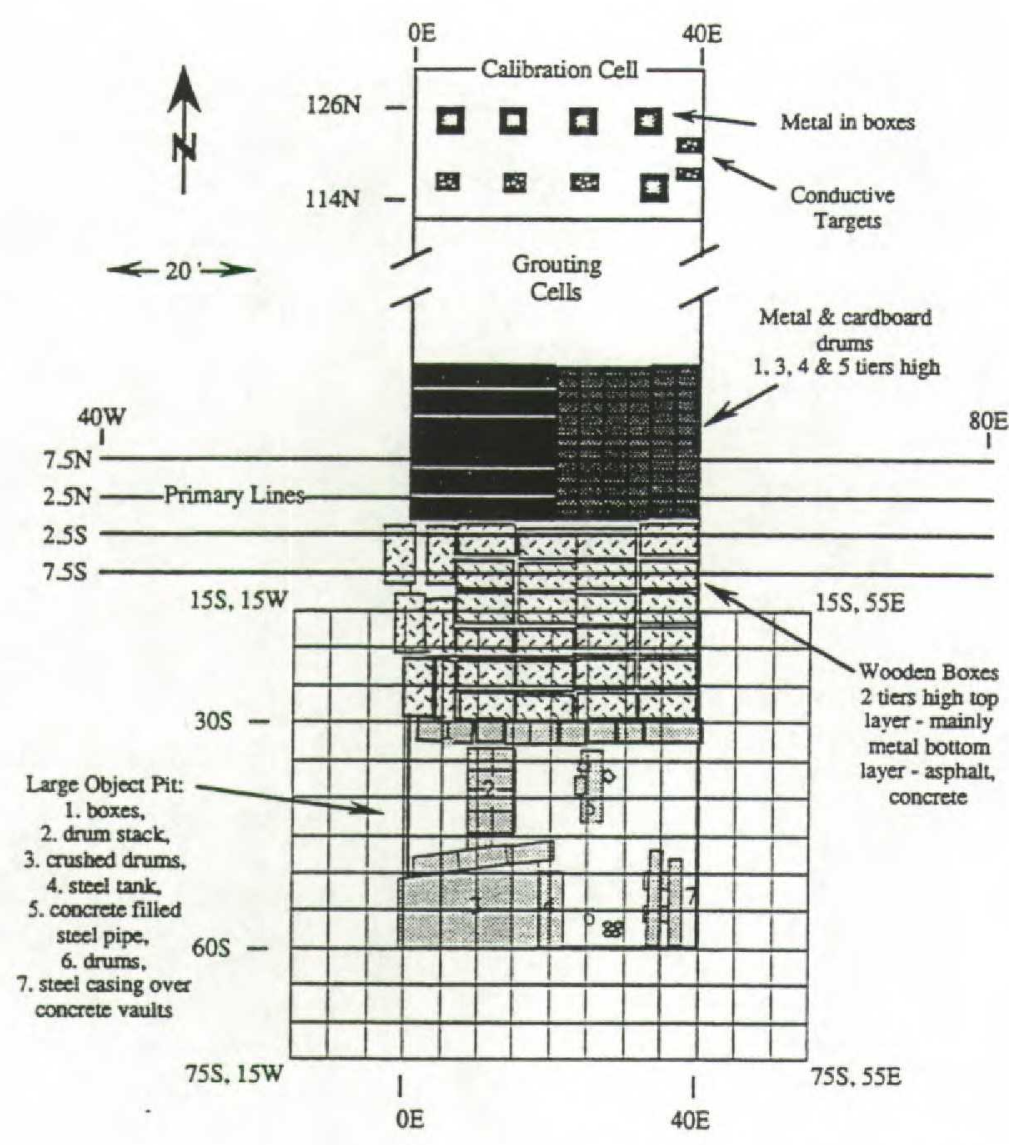

Fig. 1: Survey layout at the Idaho National Engineering Laboratory Cold Test Pit.

\section{The method}

An efficient method for waste disposal exploration is the radiomagnetotelluric method (RMT). It uses transmitters from powerful civilian and military radio stations in the frequency range 10 to $240 \mathrm{kHz}$ with possible extension to few $\mathrm{MHz}$. Horizontal components of the magnetic field are measured with a coil (diameter $0.4 \mathrm{~m}$ ) and of the electric field with two grounded electrodes spaced $5 \mathrm{~m}$ apart. Apparent resistivity and phase data are derived from these data for several selected frequencies in analogy to magnetotellurics and directly displayed in the equipment. The selection of the transmitters in the survey area is carried out by considering the strike direction of the waste site. Transmitters with similar frequencies are selected parallel and perpendicular to the general strike given by geological or anthropological structures. Assuming a twodimensional structure these data can be asssociated to the E- and B-polarization directions and can be interpreted using 2D conductivity models (Tezkan et al., 1996). 


\section{The RMT measurement}

Four transmitters broadcasting in the frequeny range $10 \mathrm{kHz}$ to $200 \mathrm{kHz}$ located perpendicular to the strike direction of the Cold Test Pit in Idaho were selected. The observed apparent resistivity and phase data show the lateral boundaries of the waste by strongly decreasing apparent resistivity values and significantly varying phase values for all frequencies on each profile crossing the waste site. The observed apparent resistivities for four frequencies on profile $7.5 \mathrm{~S}$ are demonstrated in Fig.2 as a representative example.

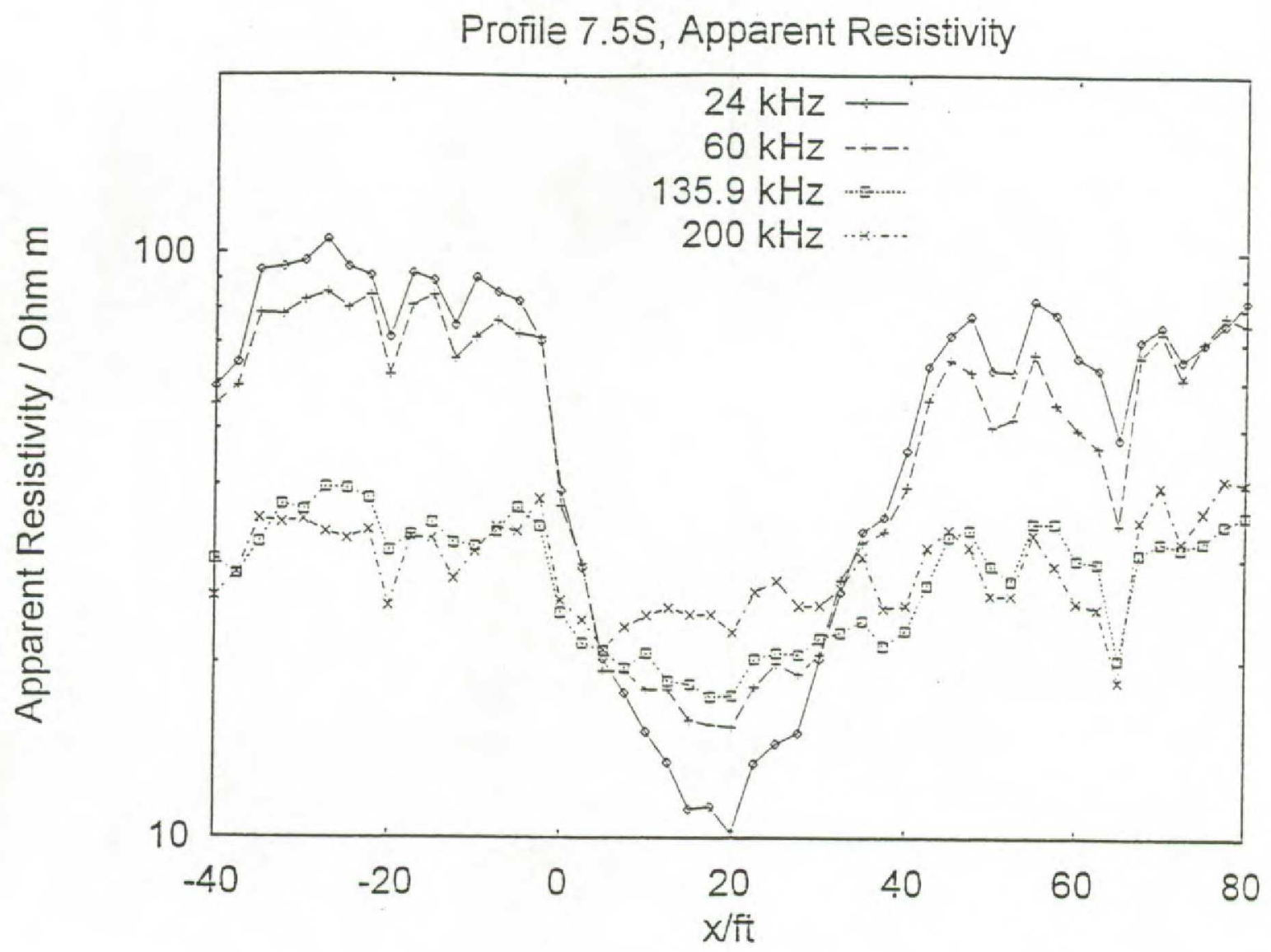

Fig. 2: Apparent resistivity of profile 7.5 S. The lateral boundaries of the waste at profile feet 0 and 40 are clearly detected.

The data were interpreted by conductivity models using 2D-inversion techniques (Smith and Booker, 1991) quantitatively. They give excellent information about the lateral limits and about the top layer. Some assumptions about the vertical extension of the waste site could also be derived by the inversion results. Fig. 3 shows the calculated $2 \mathrm{D}$ conductivity model for profile $7.5 \mathrm{~S}$ where beneath the poorly conductive top layer the highly conductive waste site is clearly resolved. 


\section{D-Inversion profile $7.5 \mathrm{~S}$}

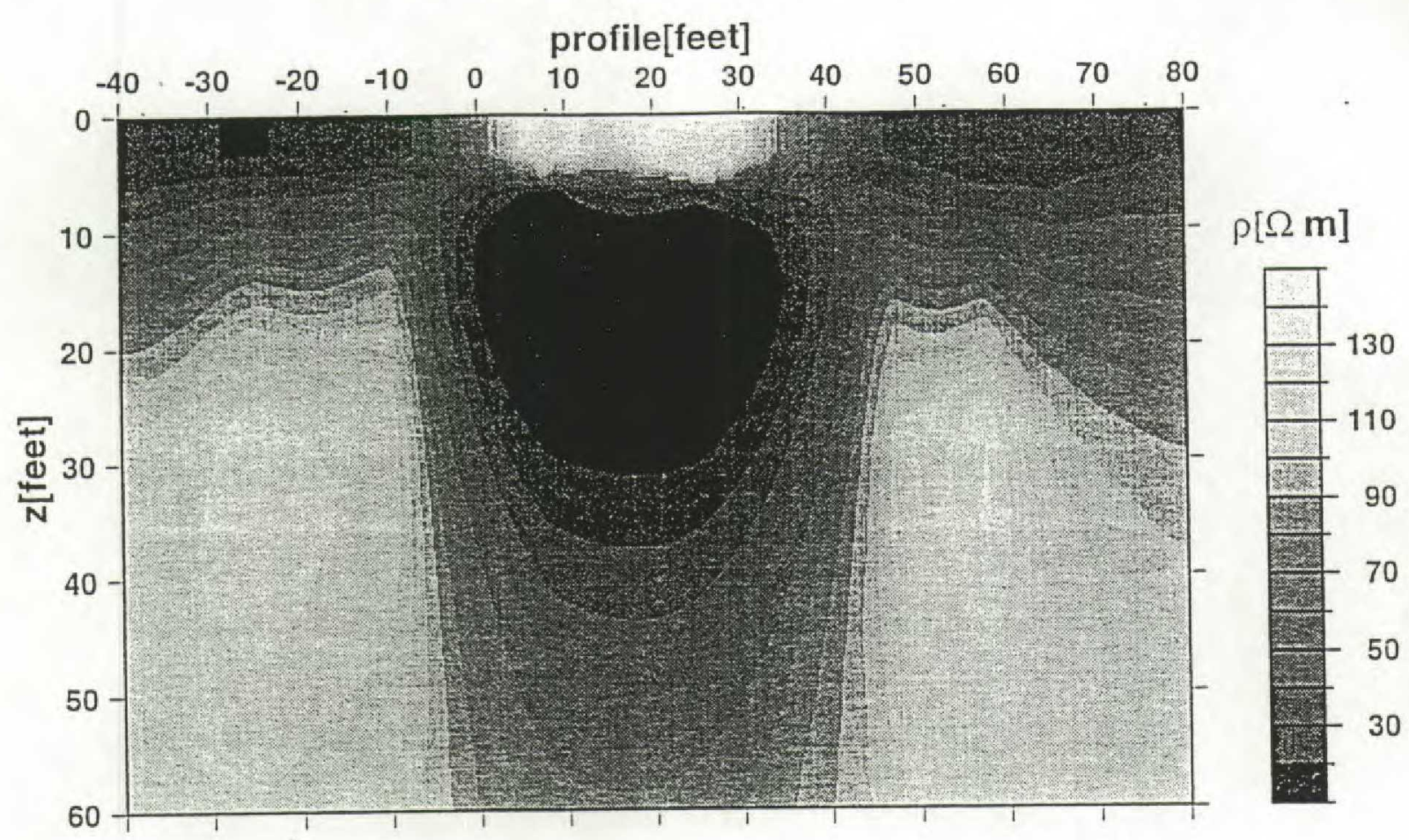

Fig. 3: A 2D conductivity model for the profile $7.5 \mathrm{~S}$.

Two dimensional inversions were carried out for all the primary lines and for the LOP. They fullfill the conditions for a 2D interpretation because of the North-South strike of the $2 \mathrm{D}$ structure of the waste site (Fig.1). Afterwards a quasi-3D conductivity distribution beneath the survey area were derived from the $2 \mathrm{D}$ inversion results.

The resolution of the lateral and vertical boundaries of the test waste site in Idaho and the resolution of different type of anomalies in the waste site using the radiomagnetotelluric method will be discussed by means of $2 \mathrm{D}$ inversion results.

\section{References}

Pellerin, L., Alumbaugh, D. L., Pfeifer, C. M., 1997. The electromagnetic integrated demonstration at the Idaho National Engineering Laboratory Cold Test Pit, extended abstract, SAGEEP, Reno / Nevada, 725-734.

Smith, J. T., und Booker, J. R., 1991. Rapid inversion of two and three dimensional magnetotelluric data. Journal of Geophysical Research, 96, B3, 3905-3922.

Tezkan, B., Goldman, M., Greinwald, S., Hördt, A., Müller, I. and Neubauer, F. M., 1996. A joint application of radiomagnetotellurics and transient electromagnetics to the investigation of a waste deposit in Cologne (Germany), Journal of Applied Geophysics, 34, 199-212. 